Www.jmscr.igmpublication.org

Index Copernicus Value: 79.54

ISSN (e)-2347-176x ISSN (p) 2455-0450

crossref DOI: https://dx.doi.org/10.18535/jmscr/v7i3.251

Journal Of Medical Science And Clinical Research

IGM Publication

An Official Publication of IGM Publication

$\underline{\text { Research Article }}$

\title{
Severe cutaneous adverse reactions to Ayurvedic drugs: a ten year study from a tertiary care centre in South India
}

\author{
Authors \\ Dr Sandhya S. Nair ${ }^{1}$, Dr Smitha Ancy Varghese ${ }^{2}$ \\ ${ }^{1,2}$ Assistant Professor Department of Dermatology Government Medical College Trivandrum, India \\ Corresponding Author \\ Dr Smitha Ancy Varghese \\ Assistant Professor Department of Dermatology Government Medical College Trivandrum, India
}

\begin{abstract}
Background: Though the system of Ayurveda has traditionally been acclaimed for its safety, questions are being raised by the scientific community regarding the documentation of safety of Ayurveda Medicines. In this article we address cases of severe cutaneous adverse reactions which are possibly related to Ayurvedic drugs.

Materials and Methods: A ten year retrospective study was carried out where the case sheets of patients admitted in dermatology ward of a tertiary care centre with cutaneous drug reactions were reviewed. Cases with clinical diagnosis of severe cutaneous adverse reactions (SJS, TEN, DRESS or AGEP) along with history of intake of Ayurvedic drugs were collected. Demographic data, clinical data, drug history and blood investigations were recorded. ALDEN scoring was done to determine causality and SCORTEN score in cases of SJS-TEN cases to assess severity.

Results: Seven out of 179 patients (3.9\%) who were admitted with SCAR (4 TEN, 2 SJS and 1 DRESS) had a history of taking Ayurvedic drugs with an ALDEN score of 2-3 implying possible causality. Most were in the 30-40 age group. Female to male ratio was 6:1.Hepatic involvement with elevated liver enzymes and hyperbilirubinemia was the commonest systemic association. Severity of disease based on SCORTEN score in patients with SJS-TEN ranged from 0-4. All the patients were treated with the withdrawal of the culprit drug and administration of systemic steroids and supportive measures. One patient out of the seven, with extensive TEN expired, thus giving a mortality rate of $14.2 \%$

Limitations: Being severe cutaneous drug reactions, drug rechallenge was not done

Conclusion: Though rare we may have to consider the potential of Ayurvedic drugs to cause even severe cutaneous adverse reactions. However to ascertain causality and identify culprit agents, collaborative studies with Ayurvedic practitioners are needed.

Keywords: Severe cutaneous adverse reactions, Ayurvedic drug reactions.
\end{abstract}

\section{Introduction}

Severe cutaneous adverse reactions (SCAR) stands for a group of drug reaction patterns that encompass Stevens-Johnson Syndrome (SJS),
Toxic Epidermal Necrolysis (TEN), Acute Generalized Exanthematous Pustulosis (AGEP) and Drug Reaction with Eosinophilia and Systemic Symptoms (DRESS). ${ }^{1}$ Studies have 
revealed that drugs like anticonvulsants, anti tuberculosis drugs, penicillins, cephalosporins, sulfa group of drugs, allopurinol and NSAIDs are more likely to produce SJS-TEN spectrum of illness. DRESS is commonly precipitated by aromatic anticonvulsants, lamotrigine, minocycline, salazopyrine and dapsone. Macrolide antibiotics, hydroxychloroquin, and diltiazem on the other hand are well known to induce AGEP. ${ }^{2}$ However studies on Ayurvedic drugs as a cause for severe cutaneous adverse reactions are lacking in literature.

Ayurveda is an ancient Indian system of Medicine being practiced in India since 1500 BC with medications based on complex herbal compounds, minerals and metal substances. The system of Ayurveda always emphasises on safe treatment which includes alleviating the disease by not instigating another disease. ${ }^{3}$ However, in practice, and also in Ayurvedic literature, untoward reactions to drugs are encountered but are not clearly addressed. Therefore, implementation of Pharmacovigilance in Ayurveda is the need of the hour to scientifically address this issue. ${ }^{4}$

In this study, the clinical data of patients who have developed severe cutaneous adverse reactions following intake of Ayurvedic drugs have been collected and analysed.

\section{Materials and Methods}

This was a retrospective observational study, extending over 10 years ( $1^{\text {st }}$ January 2005 to December 2014). The study was approved by the Institutional Ethics committee (IEC No. 05/25/2014/MCT) of Government Medical College Trivandrum in and was conducted according to the declaration of Helsinki.

The source of the data were the patient case sheets document repository facility in the Medical Records Library of our institution. These case sheets were clerked earlier by dermatology post graduate students while on ward rounds and supervised by faculty during hospital and clinical training at our institution. A total of 506 case sheets pertaining to cutaneous adverse drug reactions were utilized to procure the requisite data. Case sheets wherein the clinical diagnosis was SCAR which includes DRESS, SJS, TEN and AGEP as per Regi SCAR group recommendations were considered. Among them, patients who have taken Ayurvedic drugs in the recent past were taken. The data collection form was customized to acquire data regarding ADEs. From each case sheet, patient demographics, past medical and medication history and current medication regimen were collected. In cases were allopathic medications were co-administered, were excluded. Causality assessment using ALDEN score ${ }^{5}$ was done and only those 'probable' and 'possible' cases on causality assessment were included in the study. It may be noted that we could not obtain cases of 'very probable', as drug rechallenge was not performed. A detailed proforma containing patients' details including demographic data, drug history, clinical history, past history and comorbidities were duly filled up. In order to identify the culprit drug, the factors like drug history, temporal correlation with the drug, duration of skin lesions, time interval between the drug intake and onset of rash, morphology of drug eruption, associated mucosal or systemic involvement and improvement of lesions on withdrawal of drug were carefully analysed. In patients receiving multiple drugs, the most likely offending agent was identified on the basis of the type of reaction and the latent period between drug intake and the onset of reaction. This was further confirmed by the history of improvement on the withdrawal of the same. The results of blood and urine investigations, liver function test, renal function test, random blood sugar and in relevant cases, chest X-rays and ultrasound abdomen were recorded. The various subtypes of SCAR manifested in the study population and the associated systemic findings were studied.

\section{Results}

During the ten year study period, 10out of 179 patients $(9.4 \%)$ who were admitted in the dermatology department with SCAR with history 
of taking Ayurvedic drugs prior to onset of reactions have been selected for the study. Out of the ten, three patients who had also taken allopathic medications, were excluded. Among the remaining seven patients $(3.9 \%)$, four cases had TEN, two SJS and one DRESS. Females outnumbered the males (female to male ratio was 6:1). The youngest patient was 18 years and the oldest was 75 years, though most were in the 3040 age group.

The indications for which the Ayurvedic drug was started included improving body weight, headache, jaundice and vaginal discharge. Five patients gave a history of using only a single Ayurvedic drug prior to onset of reaction while two patients had used multiple drugs. Latent period between the drug intake and the onset of symptoms varied from 7 days to 28 days in most patients with SJS- TEN complex while it was 14 days in the patient with DRESS. The drugs prescribed were recorded along with the indication for which it was given and causality was assessed using ALDEN score as shown in Table 1. All cases had an ALDEN score of 2-3 which implies 'possible' causality.

On clinical examination, two patients had pallor and icterus, one patient (DRESS) had lymphadenopathy and five patients had fever and constitutional symptoms. One patient had hepatomegaly and one (DRESS) had hepatosplenomegaly. On routine blood examination, two patients had neutrophilia, two patients had eosinophilia and four patients had a raised ESR. On evaluating organ specific damage, hepatic involvement was encountered in four patients showing elevated liver enzymes with two patients among them showing additional hyperbilirubinemia. Two patients showed an altered renal function and hyponatremia was seen in two patients. Co-morbidities noted in this study population was carcinoma head of pancreas in one patient. Two patients in the study group gave history of drug reactions in the past to certain allopathic medications, but these drugs were not re-administered anytime in the recent past. None of the patients gave history of cutaneous adverse drug reactions in a close family member.

The severity of disease in all cases of SJS-TEN were ascertained using SCORTEN score, ${ }^{6}$ and the duration of hospital stay and final outcome were recorded as in Table2. All the patients were treated with the withdrawal of the culprit drug and administration of $1-2 \mathrm{mg} / \mathrm{kg}$ body weight of prednisolone or betamethasone equivalent, along with supportive measures. The only patient who didn't improve was a 19 year old female who developed TEN following Ayurvedic drug taken for vaginal discharge. She had widespread erosions, developed sepsis,liver derangements, metabolic acidosis and hyponatremia and expired on the $7^{\text {th }}$ post-admission day inspite of administering high dose steroids and broad spectrum antibiotics, thus contributing to a mortality rate of $14.2 \%(1 / 7)$ among the patients with SCAR to Ayurvedic drugs in this study group. All other patients had relief of symptoms and were discharged with an average hospital stay of 12 days.

Table: 1 Causality of SCAR due to Ayurvedic drugs was calculated using ALDEN score.

\begin{tabular}{|l|c|c|}
\hline Ayurvedic drug used & $\begin{array}{c}\text { Indication of } \\
\text { drug }\end{array}$ & ALDEN score \\
\hline Single polyherbal drug & $\begin{array}{c}\text { Vaginal } \\
\text { discharge }\end{array}$ & 3 \\
\hline $\begin{array}{l}\text { Multiple polyherbal } \\
\text { drugs }\end{array}$ & Jaundice & 2 \\
\hline Single polyherbal drug & $\begin{array}{c}\text { Improving body } \\
\text { weight }\end{array}$ & 3 \\
\hline Single polyherbal drug & Headache & 2 \\
\hline $\begin{array}{l}\text { Single polyherbal drug } \\
\text { (Chyavanaprasam) }\end{array}$ & $\begin{array}{c}\text { Improving body } \\
\text { weight }\end{array}$ & 3 \\
\hline Single polyherbal drug & Headache & 3 \\
\hline $\begin{array}{l}\text { Multiple polyherbal } \\
\text { drugs }\end{array}$ & Jaundice & 3 \\
\hline
\end{tabular}

Table: 2 Severity of Drug reaction on SCORTEN evaluation, final outcome and duration of hospital stay

\begin{tabular}{|l|c|c|c|c|}
\hline Patient & $\begin{array}{c}\text { SCORTEN } \\
\text { score }\end{array}$ & $\begin{array}{c}\text { Predicted } \\
\text { mortality }\end{array}$ & $\begin{array}{c}\text { Final } \\
\text { outcome }\end{array}$ & $\begin{array}{c}\text { Hospital } \\
\text { stay }\end{array}$ \\
\hline 1 & 3 & 35.3 & Death & 17 \\
\hline 3 & 0 & 3.2 & Relieved & 6 \\
\hline 4 & 0 & 3.2 & Relieved & 5 \\
\hline 5 & 1 & 3.2 & Relieved & 8 \\
\hline 6 & 3 & 35.3 & Relieved & 23 \\
\hline 7 & 4 & 58.3 & Relieved & 14 \\
\hline
\end{tabular}




\section{Discussion}

Although the National Pharmacovigilance Program of India has encouraged reporting of all suspected drug-related adverse events including those caused by herbal/traditional/alternative medicines (Protocol of NPP, Version 1, 2004, p. 17), the number of reports related to ayurvedic/herbal drugs has been emphatically low. ${ }^{4}$ Moreover owing to the firmly held belief among Ayurveda practitioners and patients alike, that ayurvedic drugs are safe, accessing data regarding adverse reactions has become a major challenge. Right from obtaining a correct history, recognising the signs and symptoms of a drug reaction, identifying the culprit medicine to proper reporting of adverse drug events, all steps pose as major obstacles. ${ }^{7}$

Herbal treatments are becoming increasingly popular particularly in the field of dermatology. Thus it has become essential for dermatologists to know about their potential adverse effects.

According to Lee et $\mathrm{al}^{8}{ }^{8}$ virtually all herbal remedies can cause allergic reactions and several can be responsible for photosensitization. Some herbal medicines, contain arsenic or mercury that can produce typical skin lesions as well as systemic complications. Some popular herbal remedies that are known to cause dermatological side-effects include St John's Wort, kava, aloe vera, eucalyptus, camphor, henna and yohimbine. $^{9}$

In a study done on SJS in Indian patients, out of 225 patients with SJS, four patients had Ayurvedic drugs as the causative agent (1.02\%). ${ }^{10}$ In our study on patients having SCAR which includes DRESS, SJS, TEN and AGEP, it wasfound that 10patients out of 179 patients (9.4\%) who presented with SCAR and had Ayurvedic medications prior to development of drug reaction. An ALDEN score was done in all cases to establish causality. Seven patients had an ALDEN score of (2-3) which implies possible causality, so they were included in the study while three patients had a score of 0-1 which implies unlikely causality and therefore were not considered. So the overall percentage of patients who have developed SCAR which maybe attributable to Ayurvedic drugs among the total patients with SCAR in this study period is $3.4 \%$.

The female to male ratio was $6: 1$ and this trend of a female preponderance was also seen in a study conducted by Ajanal et al ${ }^{11}$; though only a slightly higher incidence of adverse drug reactions i.e.(1.3:1) was noticed. This may be due to the small study population in our study. The most common age group affected were those of middle age while most Ayurvedic literature categorise the elderly population as the most susceptible group. The reason cited being that females and older age group are believed to have low immunity (Alpabalayukta) and more susceptible for drug sensitivity. ${ }^{12,13}$

Causality assessed by ALDEN score revealed a score of 2-3 in all cases which implies 'possible' causality. Furthermore all the formulations in this study comprised of polyherbal formulations with no patients who had taken herbal-biomineralformulations known as Rasaoushadam, which are implicated in most cases of systemic toxicities. ${ }^{14}$ Ayurvedic practitioners vouch on the efficacy and safety of most drugs but also suggest procurement of this herb mix only from reputable sources. Supplements purchased from a non-reputable source or manufacturer may contain additives or toxins which may result in the adverse effects upon consumption. ${ }^{15}$

The most common symptom was pruritus, followed by rash and constitutional symptoms. These findings are similar to the study by Ajanal et al. ${ }^{11}$ The most common system affected apart from skin, was the gastrointestinal system,with hepatotoxicity being the most pronounced characterised by the elevated liver enzymes. A major reason for the unsubstantiated lack of incidence of Ayurvedic drug induced hepatotoxicity is the difficulty in proving causality, especially when using multi-ingredient and often unlabelled products and when all other causes of liver disease have not been meticulously ruled out. Nevertheless, medical 
providers, particularly gastroenterologists and hepatologists, will attest to the occurrence of hepatotoxicity as part of drug reaction to Ayurvedic drugs as patients seek medical care when they develop severe liver disease. ${ }^{16}$

Regarding mortality as a part of drug reactions to Ayurvedic drugs, a 19 year old female who developed TEN following Ayurvedic drug taken for vaginal discharge had succumbed to sepsis, metabolic acidosis and hepatotoxicity. She had a SCORTEN score of 4 which is associated with a mortality of $48 \%$.Severe disease leading to mortality $(4.8 \%)$ were reported in a study that was done on traditional Chinese polyherbal medications. ${ }^{17}$ Also in a study from south India also showed mortality following drug induced liver injury, especially when drugs contained heavy metals and hepatotoxic volatile organic compounds (hVOCs). ${ }^{18}$

\section{Limitations}

Being severe cutaneous drug reactions, drug rechallenge was not done in any case due to which we could not categorise the drug as 'probable' and 'very probable' on causality scoring. Also due to small number of patients, statistical tests were not done. Content of the polyherbal preparations and whether they were purchased from authentic Ayurvedic sources were not determined.

\section{Conclusion}

It is time to consider the possibility that alternative systems of medicines can have side effects, which can at times be severe. However identifying the culprit agent may prove to be a challenge with Ayurvedic medicines as Ayurveda gives ample scope for the use of medicines based on various factors like Prakruti, Desha, Kala, etc., So the combination becomes multifold and there is a lack of uniformity from patient to patient and physician to physician. Also, proprietary medicines are also combined with the classical preparations making it further more complicated. ${ }^{19}$ Therefore intense efforts in collaboration with Ayurvedic practitioners to ascertain causality and delineate the culprit agent is absolutely the need of the hour.

\section{References}

1. Roujeau JC, Allanore L, Liss Y, Mockenhaupt M. Severe Cutaneous Adverse Reactions to Drugs (SCAR): Definitions, diagnostic criteria, genetic predisposition. Dermatol Sinica. 2009; 27:203-9.

2. Breathnach SM. Drug reactions. In: Burns T, Breathnach S, Cox N, Griffiths C, editors. Rook's Textbook of Dermatology. 8th ed. Vol. 75. UK: WileyBlackwell; 2010. pp. 1-177.

3. Acharya J.T., editor. "Chikitsastana" Charaka Samhita.5th ed. Chaukhambha Sanskrit Sansthan; Varanasi: 2006.647, 412, 138-150, 22, 234, 276, 702,693, 704, 247.

4. Rajesh B, Devangi RD, Anjum W. Assessment of knowledge, attitude and practice of pharmacovigilance among doctors practicing alternative systems of medicine in Southern India: A questionnaire based study. Natl J Physiol Pharm Pharmacol. 2017;7:1-4.

5. B Sassolas, C Haddad, M Mockenhaupt A Dunant, Y Liss, K Bork, ALDEN, an algorithm for assessment of drug causality in Stevens-Johnson Syndrome and toxic epidermal necrolysis: comparison with case-control analysis Clin Pharmacol Ther 2010 88:60-68.

6. S Bastuji-Garin, N Fouchard, SCORTEN:

a severity-of-illness score for toxic epidermal necrolysis J Invest Dermatol 2000 115:149-53.:149-53.

7. Thatte U, Bhalerao S. Pharmacovigilance of Ayurvedic medicines in India. Indian $\mathbf{J}$ Pharmacol. 2008;40(Suppl 1):S10-2.

8. Systematic Review of Adverse Effects from Herbal Drugs Reported in Randomized Controlled Trials.Lee JY, Jun SA, Hong SS, Ahn YC, Lee DS, Son 
CG.Phytother Res. 2016 Sep;30(9):14129.

9. Taniya T, Nardev S. A Review on Side Effects of Herbal Drugs. World Journal of Pharmacy and Pharmaceutical Sciences 2016; 5(6): 2150-2164.

10. Patel TK, Barvaliya MJ, Sharma D, Tripathi C. A systematic review of the drug-induced Stevens-Johnson syndrome and toxic epidermal necrolysis in Indian population. Indian J Dermatol Venereol Leprol 2013;79:389-98.

11. Ajanal MN, Nayak SU, Kadam AP, Prasad B S. Pharmacovigilance study of Ayurvedic medicine in Ayurvedic Teaching Hospital: A prospective survey study. AYU 2015;36:130-7.

12. Acharya JT, editor. Charaka Samhita of Charaka, Vimana Stana, Ch. 8, Ver. 122. $5^{\text {th }}$ ed. Varanasi: Chaukhambha Sanskrit Sansthan; 2006. p. 280.

13. Sharma PV, editor. Sushruta Samhita of Sushruta, Sootra Stana, Ch. 35, Ver. 32. $1^{\text {st }}$ ed. Varanasi: Chaukhamba Orientalia; 2005. p. 228.

14. Saper RB, Kales SN, Paquin J, Burns MJ, Eisenberg DM, Davis RB, et al. Heavy metal content of Ayurvedic herbal medicine products. JAMA. 2004;292:2868-73.

15. Tarasiuk A, Mosińska P, Fichna J. Triphala: current applications and new perspectives on the treatment of functional gastrointestinal disorders. Chinese Medicine 2018;13:39.

16. Devarbhavi, H. Ayurvedic and herbal medicine-induced liver injury: It is time to wake up and take notice. Indian $\mathbf{J}$ Gastroenterol (2018) 37: 5.
17. Zhu Y, Niu M, Chen J, et al. Hepatobiliary and pancreatic: comparison between Chinese herbal medicine and Western medicine-induced liver injury of 1985 patients. J Gastroenterol Hepatol. 2016;31:1476-82.

18. Philips CA, Paramaguru R, Joy AK, Antony KL, Augustine P. Clinical outcomes, histopathologic patterns and chemical analysis of ayurveda and herbal medicine associated with severe liver injury - a single center experience from South India. Indian J Gastroenterol. 2018; 37.

19. Sharma R, Galib R, Prajapati PK. Good Pharmacovigilance Practice: Accountability of Ayurvedic Pharmaceutical Companies. Ancient Science of Life. 2017;36(3):167-169. 